\title{
Research on Characteristics of Foreshocks of the Dengta M5.1 Earthquake Sequence in Liaoning
}

\author{
Xiaoshan Wang ${ }^{1, \text { a }}$, Yimei Sun ${ }^{2}$, Liang Wang ${ }^{2}$, and Li Ma ${ }^{2, *}$ \\ ${ }^{1}$ Hebei Earthquake Agency, 050021 Shijiazhuang Hebei, China \\ ${ }^{2}$ Liaoning Earthquake Agency, 110031 Shenyang Liaoning, China
}

\begin{abstract}
With the observed earthquake sequence data and the waveform data in the hypocenter region of the M5.1 earthquake that hit Dengta County in Liaoning on $23^{\text {rd }}$ January, 2013, this study calculated the amplitude spectrum correlation coefficient before and after the M5.1 earthquake, and performed data clustering. Meanwhile, through comparing the focal mechanism of the mainshock and the maximum foreshock, this study explored whether the Dengta M5.1 Earthquake had foreshocks, and found that the foreshocks of Dengta earthquake had a consistent focal mechanism.
\end{abstract}

\section{Introduction}

On the evening of $21^{\text {st }}$ May, 2021, Yangbi County of Dali Prefecture of Yunnan was hit by several aboveM4.0 earthquakes, with the maximum earthquake reaching a magnitude of 6.4. The earthquake left three dead and 32 injured. Earthquakes often lead to immeasurable damages to human life and properties, and hence earthquake prediction has become an eternal topic among seismologists. Foreshocks are considered the most effective indicator among all short-imminent seismic precursors for earthquake prediction ${ }^{[1]}$. Early researchers, from the angle of seismic source spectra, maintained that there were abnormal high-frequency parts in the amplitude spectra of foreshocks ${ }^{[2]}$, and this argument was confirmed by the experimental studies later ${ }^{[3]}$. The earthquake focal mechanism consistency, which is considered the most important measure for foreshock detection, is a salient feature of foreshock sequences ${ }^{[4]}$. Recent studies on foreshock sequences based on observed data also revealed highly similar seismic waves of foreshocks $\left[{ }^{5-6]}\right.$. Among other methods that followed the same logic is the amplitude spectrum correlation coefficient ${ }^{[7-8]}$ : a high amplitude spectrum correlation coefficient in fact indicates a consistent earthquake focal mechanism. The occurrence of foreshocks is related to the formation environment. For instance, the Yingkou - Haicheng - Xiuyan region in Liaoning has a high possibility to see foreshock sequences, and except for the Magnitude 7.3 earthquake in Haicheng in 1975, the Xiuyan - Haicheng M5.6 Earthquake that took place in 1999 showed typical foreshocks ${ }^{[9]}$. On $23^{\text {rd }}$ January, 2013, a M5.1 earthquake hit Dengta County in Liaoning. Likewise, this earthquake also took place in Liaoning. In this study, several seismologic methods were employed to explore

\footnotetext{
* Corresponding author: rongcuoxue@163.com.

a pragueboy@163.com
}

whether there were foreshock sequences in the Dengta Earthquake.

\section{The earthquakes in Dengta area}

On $23^{\text {rd }}$ January, 2013, a M5.1 earthquake hit the junction between Dengta County of Liaoyang City and Sujiatun District of Shenyang City in Liaoning. This region had seen few earhtquake before this M5.1 Earthquake. Though in 2001, several earthquakes with magnitude 1-2 hit this region, no earthquake with a magnitude over 2.5 was recorded. Between 2002 and 2008 , this region showed no obvious earthquake activity, and since 2009 it has seen increasing earthquakes with increasing magnitudes (Figure 1).

\section{The focal mechanism consistency}

The Dengta M5.1 earthquake sequence were sequenced by the time: the earthquake $n$ and the preceding $(n-1)$ earthquakes were grouped into one sequence, which was moved with 1 as the step size to calculate the arithmetic mean of the amplitude spectrum correlation coefficient and hence the amplitude spectrum correlation coefficient that changed with the time $\mathrm{e}^{[8]}$ as well as the clustering tree. The difference of earthquake focal mechanism between earthquakes was therefore obtained to explore the spatiotemporal change characteristics of the earthquake focal mechanism of the Dengta earthquake sequence.

Specific research steps are as follows. First, four monitoring stations with an interspace angle with the stations around the area of principal shocks smaller than $180^{\circ}$ were selected, the data of earthquakes with a magnitude smaller than 2.3 was removed because the phase of earthquakes with a small magnitude is unclear and will result in errors in the calculation result. An amplitude spectrum correlation coefficient analysis 
program was employed to analyze the data, and the seismic waves of 31 earthquakes were extracted. Different lengths of time windows were selected to ensure that the main energy of the $\mathrm{P}$ waves and $\mathrm{S}$ waves was within the time window. A higher recognition level of the waves was preferred, and the length was usually set at 2000, and the length would be extended in the case
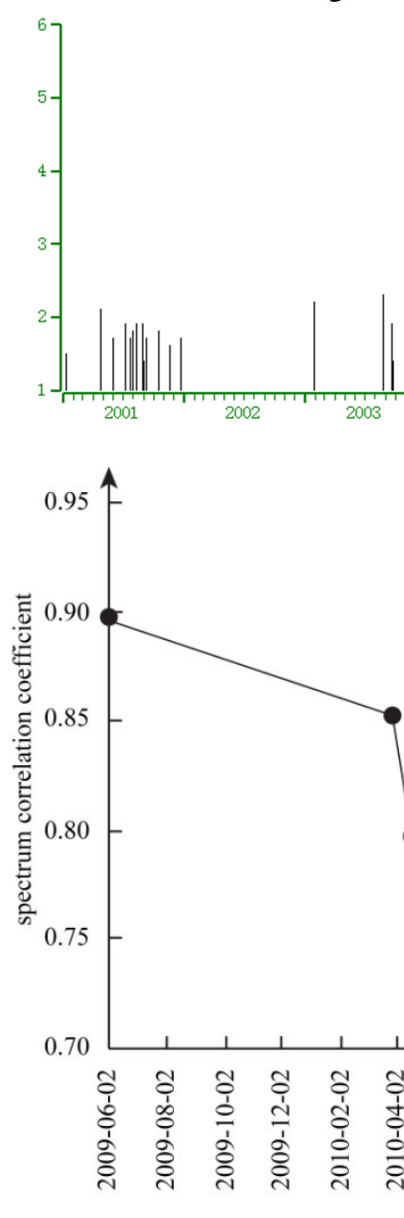

of strong earthquakes. After horizontal correction of the wave shape, the $\mathrm{P}$ wave sequence and $\mathrm{S}$ wave sequence of different weights in the seismic wave were computed to obtain the Fourier spectra of the observed waves: the velocity spectra and the displacement spectra. The amplitude spectrum correlation coefficients of 31 earthquakes were obtained (Figure 2).

Figure 1. M-t diagram of Dengta County of Liaoning

As Figure 2 shows, there is tangible earthquake focal mechanism consistency in the earthquakes before the Magnitude-5.1 Earthquake that hit Dengta on $23^{\text {rd }}$ January, 2013. The coefficients of the several earthquakes circled in Figure 4 were above 0.9; the arrow marked the time point where the principal shock turned up; $t$ he amplitude spectrum correlation coefficient post the earthquakes were all below 0.85 , indicating that there was no longer obvious earthquake focal mechanism consistency. This presents the time series changing characteristics of the earthquake focal mechanism consistency of the seismic sequence of the Dengta Earthquake.

The multi-spectrum correlation coefficients of 31 earthquakes underwent clustering analysis, and the maximum-length method was used as the clustering method. This method was a successive clustering method, and the binary-tree cluster diagram for the last cluster was obtained. Based on the 31 measured values, the distance between clusters was calculated, and the adjacent two observed values were grouped into one cluster, while single observed values that had not been grouped were set as one cluster. Figure 3 shows the clustering result.

As Figure 3 shows, there were four sets of events in the clustering trees. In the first set, the maximum length is within 0.1 , which is considered to have similar earthquake focal mechanism within the set; in the second set, the maximum distance is within 0.15 , which is considered to have relatively similar earthquake focal mechanism within the set; in the third and fourth sets, the maximum distance is above 0.2 , which is considered to have dissimilar earthquake focal mechanism in the set. Overall, most seismic events had similar earthquake focal mechanisms, and the events that showed inconsistency of earthquake focal mechanisms were 5, $25,24,7,8$, and 21 .

In sum, during the foreshocks, the earthquake focal mechanism presented changes from a scattered pattern to a consistency pattern. From $1^{\text {st }}$ January, 2008 to $23^{\text {rd }}$ January, 2013 when the Magnitude-5.1 earthquake that hit Dengta, there were a total of 19 earthquakes, among which only three had dissimilar earthquake focal mechanisms. There were 12 earthquakes that happened 
after the Magnitude 5.1 Earthquake, among which an increasing proportion of earthquakes showed inconsistent earthquake focal mechanisms. Thus, it could be concluded that there was advantageous earthquake focal mechanism distribution in the Dengta earthquake sequence, which is correlated to the geometric features of the causative faults. The small earthquakes that took place before the principal shock showed similar earthquake focal mechanisms, which is the features of foreshocks; at the start of the sequence, the earthquake focal mechanism was disordered and became divergent.

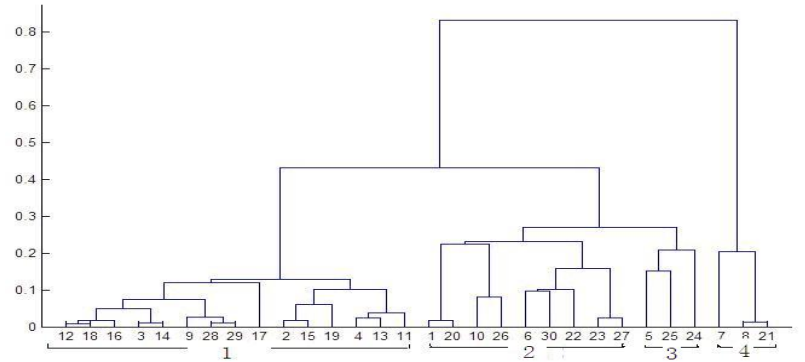

Figure 3. Results of clustering trees

\section{The focal mechanism solution of the mainshock and the maximum foreshock}

The recorded seismic waves observed from 26 monitoring stations with a high signal-to-noise ratio and within $200 \mathrm{~km}$ from the hypocenter were selected, the Pwave first motion inversion method was employed to invert the focal mechanism solution of the Dengta M5.1 Earthquake. This earthquake is a strike-slip earthquake. For nodal plane $\# 1$, the strike is $284^{\circ}$, the dip is $84^{\circ}$, and the slip angle is $-176^{\circ}$; for nodal plane $\# 2$, the strike is $15^{\circ}$, the dip is $87^{\circ}$, and the slip is $-5^{\circ}$. On the $\mathrm{P}$ axis, the azimuth angle is $240^{\circ}$, and the plunge is $6^{\circ}$; on the $\mathrm{T}$ axis, the azimuth angle is $149^{\circ}$, and the plunge is $3^{\circ}$; on the $\mathrm{B}$ axis, the azimuth angle is $36^{\circ}$, and the plunge is $83^{\circ}$. The Dengta M5.1 earthquake is a strike-slip earthquake. The calculation result shows that the stations were evenly distributed, and the results concentrated on the $\mathrm{P}$ and $\mathrm{T}$ axes, with the contradiction ratio 0 (Figure 4).

Before the Dengta M5.1 Earthquake, the maximum earthquake that hit the region was a M4.1 earthquake that took place on 4th April, 2012. By the same method, the P-wave first motion data were used to calculate the focal mechanism solution of this earthquake, and the earthquake was identified as a strike-slip earthquake. The specifics of this earthquake are as follows: on the nodal plane $\# 1$, the orientation is $204^{\circ}$, the dip is $85^{\circ}$, and the slip is $3^{\circ}$; on the nodal plane $\# 2$, the strike is $294^{\circ}$, the dip is $87^{\circ}$, and the slip is $5^{\circ}$; on the $\mathrm{P}$ axis, the azimuth angle is $69^{\circ}$ and the plunge is $1^{\circ}$; on the $\mathrm{T}$ axis, the azimuth angle is $159^{\circ}$ and the plunge is $6^{\circ}$; on the $\mathrm{B}$ axis, the azimuth angle is $326^{\circ}$ and the plunge is $84^{\circ}$. Figure 5 shows the calculation result.

Comparison of the focal mechanism between the two earthquakes shows that both are strike-slip earthquakes, with an plunge of $\mathrm{P}$ and $\mathrm{T}$ axes larger than $25^{\circ}$, and horizontal compression as the major cause. As regional stress field reflected by the small earthquake composite fault-plane solution in the Shenyang-Liaoyang area since
1974 shows, the composite earthquake focal mechanism solution of the many small earthquakes in history on the $\mathrm{P}$-axis direction is between $52^{\circ}$ and $86^{\circ}$, averaged at $72^{\circ}$; on the T-axis direction, the solution ranges from $149^{\circ}$ to $176^{\circ}$, with a mean of $161^{\circ}$. The plunge of the $\mathrm{P}$ axis is between $2^{\circ}$ and $46^{\circ}$, with a mean of $16^{\circ}$; the plunge of the $\mathrm{T}$ axis is between $2^{\circ}$ and $12^{\circ}$, with a mean of $7^{\circ}$. In all, the M5.1 earthquake that hit Dengta in 2013 and the M4.4 earthquake that hit Dengta in 2012 showed that the Shenyang-Liaoyang stress field and the regional stress field were consistent, the principal pressure axis that constructed the stress field was the NEE direction, the principal tensile stress axis is along the NNW direction, and the principal stress mainly works along the horizontal direction. Under this stress field, the northeasterly faults are prone to dextral strike-slips, and the northwesterly faults are prone to sinistral strike-slips.

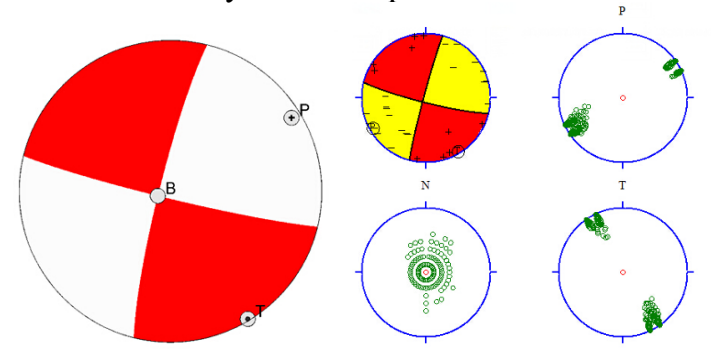

Figure 4. The focal mechanism of the M5.1 earthquake in Dengta on $23^{\text {rd }}$ January, 2013
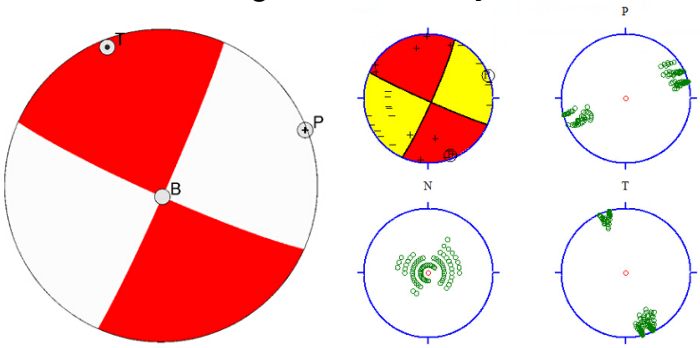

Figure 5. The focal mechanism solution of the M4.1 Earthquake on $4^{\text {th }}$ April, 2012

\section{Conclusion and discussions}

In this study, the body-wave amplitude spectrum correlation coefficient method was calculated and it was found that the amplitude spectrum correlation coefficients of Dengta Earthquake on 23rd January, 2013 and several foreshocks had an amplitude spectrum correlation coefficient above 0.9 , while the coefficient after this earthquake was below 0.85 , which indicates that the earthquakes after the Dengta M5.1 Earthquake had no obvious earthquake focal mechanism consistency. The foreshocks of the M5.1 earthquake that hit Dengta on 23rd January, 2013 showed obvious earthquake focal mechanism consistency; as the earthquake focal mechanism solution of the mainshock and the maximum foreshocks was similar, the focal mechanism of foreshocks within the hypocenter area changed from a scattered pattern to a consistent pattern, and showed advantageous focal mechanism distribution, which is considered to be related to the geometric features of the causative fault. Therefore, the sequence had foreshocks, and the small shocks before the mainshock might have 
similar focal mechanisms. Meanwhile, the focal mechanisms of aftershocks presented scattered.

It is, however, illogical to rely on this single feature to identify whether there are foreshocks, and more indepth analysis of the earthquake sequence should be performed. As the nucleation of an earthquake starts, it will result in instability ${ }^{[10-11]}$. Foreshocks are an important part of the nucleation process of an earthquake, i.e., the direct evidence of accelerated deformation before instability ${ }^{[12]}$, and the expected typical microseismic events before the sub-instability stage in the subinstability theory ${ }^{[13]}$. Therefore, effective detection of foreshocks is the direct evidence to evaluate whether there will be subsequent macro-instability. Despite the lots of studies having been done in the past, there is still no effective foreshock recognition method available ${ }^{[14]}$. The rupture growth and strike-slip displacement of the nucleation of the foreshocks expand with the time, and may incur migration of small shocks towards the principal shock hypocenter. In contrast, there are no significant expansion or migration of earthquakes in common earthquake swarms ${ }^{[15]}$.

Acknowledgements This research is funded by the seismic research project of Changning, Sichuan (IGCEA1919).

\section{References}

1. Jones, L. M., Molnar, P. (1979) Some characteristics of foreshocks and their possible relationship to earthquake prediction and premonitory slip on fault. J. Geophys. Res., 84(B7): 3596-3608.

2. Zheng, J. C., Wang, P., Xu, C. T., Xu, F. F. (2015) Analysis of seismic spectra of the 2014 Yutian Ms7.3 Earthquake sequence and foreshock recognition. Earthquake Research in China, 31(02): 253-261.

3. Jiang, H. K. (2000) Typical fault complexes and sound emission characteristics of rock deformation under different temperatures and pressures. Institute of Geology, China Earthquake Administration, Beijing, 28-56.

4. Chen, Y. (1978) Earthquake focal mechanism consistency as a new parameter for seismic activity. Chinese Journal of Geophysics, 21(2):46-159.
5. Ni, S. D., Wang, W. T., Li, L. (2010) Yushu Earthquake on 14 ${ }^{\text {th }}$ April, 2010: A destructive earthquake with foreshocks, Scientia Sinica(Terrae), 40(5): 535-537.

6. Bouchon, M., Karabulut, H., Aktar, M., Özalaybey, S., Schmittbuhl J., Bouin, M-P. (2011) Extended nucleation of the $1999 \mathrm{Mw} 7.6$ Izmit earthquake. Science, 331(5): 877-880.

7. Lund, B., Boevarsson, R. (2002) Correlation of microearthquake body wave spectral amplitudes. Bull. Seismol. Soc. Am., 92(6): 2419-2433.

8. Cui, Z. J., Li, Z. X., Chen, Z. L. Zhao, C. P., Zheng, S. H., Zhou, L. Q. (2012) Research on new methods for classification of small earthquake swarm sequences - amplitude spectrum correlation analysis, Chinese Journal of Geophysics, 55(5): 1718-1724.

9. Yu, L. W., Li, F., Lu, L. Y., Chi, G. C., Wang, H. Y. (2000) Scientific summary of successful forecast of the Magnitude-5.6 Xiuyan-Haicheng Earthquake on 29 ${ }^{\text {th }}$ November, 1999. Seismological Research of Northeast China, 16(2): 14-26.

10. Das, S., Scholz, C. H. (1981) Theory of time dependent rupture in the earth, J Geophys Res, 86(B7): 6039- 6051.

11. Kanamori, H. (1981) The nature of seismicity patterns before large earthquake. In: Simpson, D. W., Richards, P. G. (Eds.), Earthquake Prediction: An International Review, American Geophysical Union, (4): 1-19.

12. Scholz, C. H. (2002) The mechanics of earthquakes and faulting. Cambridge University Press, New York.

13. Ma, J., Sherman, S. I., Guo, Y. S. (2012) Recognition of stress sub-instability before earthquakes - an experimental case study on the temperature evolution of a $5^{\circ}$ bend fault. Scientia Sinica(Terrae), 42(5): 633-645.

14. Jiang, H. K.,Zhou, S. H. (2020) Foreshocks: the value of forecast and recognition methods. Seismological and Geomagnetic Observation and Research, 41(05): 222-225.

15. Qu, J. H., Jiang, H. K., Li, J., Zhang, Z. H. Zheng, J. C. Zhang, Q. (2015) A brief analysis of the seismogenic structure of the earthquake sequence that hit Rushan of Shandong from 2013 to 2014. Chinese Journal of Geophysics, 58(6):1954-1962. 